\title{
Contos de fadas na educação infantil: preparando professores para formar leitores
}

Fairy tales in early childhood education: preparing teachers to train readers

\section{Andréa Scopel Piol}

\section{Poliana Bernabé Leonardeli²}

1 Graduada em Pedagogia. Mestra em Ensino na Educação Básica pelo Programa de Pós-graduação em Ensino na Educação Básica da UFES/CEUNES (Mestrado Acadêmico). Pedagoga da Rede Municipal de Ensino de Aracruz, ES, e Professora da Faculdade Pública de Ensino Superior de Linhares - FACELI. E-mail: andrea_scopel@hotmail.com.

2 Graduada em Letras. Mestra em Estudos Literários pelo Programa de Pós-graduação em Literatura da Ufes (Mestrado Acadêmico). Professora de Língua Portuguesa da Rede Estadual de Linhares, ES, e Professora da Faculdade Pública de Ensino Superior de Linhares - FACELI. E-mail: pleonardeli@ gmail.com. 
RESUMO: O artigo objetiva divulgar um projeto de extensão desenvolvido por estudantes do curso de Pedagogia da Faculdade de Ensino Superior de Linhares - FACELI, em escolas públicas de Educação Infantil do município do qual a instituição faz parte. $\mathrm{O}$ material deste trabalho possibilita uma reflexão sobre a importância da formação do professor de Educação Básica como formador de leitores, uma vez que o uso da literatura se faz urgente na prática docente. A importância do projeto dá-se devido ao gênero Conto de Fadas, quando trabalhado de forma eficiente, ser instrumento capaz de oportunizar a interação da criança com o universo da imaginação e também aprimorar ainda mais o desenvolvimento crítico do educando em formação. Nesse contexto, o artigo busca demonstrar a importância do projeto desenvolvido pela instituição de Ensino Superior ao comprovar que, pela prática dos estudantes envolvidos, há possibilidade de estimular e incentivar as crianças para o conhecimento literário, que não acontece só por meio de livros, mas também pela imersão em espaços literários, o que ocorre, no caso, por meio de projetos de leitura como o que aqui será apresentado.

PALAVRAS-CHAVE: Literatura Infantil; Ensino; Contos de Fadas; Projeto de Extensão.

ABSTRACT: The article aims to disseminate an extension project developed by students of the Pedagogy course at the Faculty of Higher Education of Linhares - FACELI, in the public schools of Early Childhood Education of the municipality that qualifies an institution that is part of. The material of this work allows a reflection on the importance of the basic education teacher training as a reader trainer, since the use of literature makes it urgent in teaching practice. The importance of the project is due to the fairy tale genre, when worked efficiently, it is an instrument capable of creating opportunities for the child's interaction with the universe of imagination and also improving even more the critical development of teaching in training. In this context, the article seeks to demonstrate the importance of the project developed by the institution of higher education, proven by the practice of students, which can use and stimulate children for literary knowledge, which occurs not only in the middle of books, but also by immersion in literary spaces, which occurs, in this case, through reading projects such as the one presented here.

KEYWORDS: Children's Literature; Teaching; Fairy tale; Extension project. 


\section{Introdução}

O artigo propõe divulgar, por meio de suporte teórico, relatos, fotos e outros materiais desenvolvidos, um projeto de formação leitora promovido por uma Instituição de Ensino Público Superior. O projeto de extensão em questão, iniciado no primeiro semestre de 2018, chamado Contos de Fadas na Educação Infantil, objetivou alcançar e atender escolas de Educação Infantil geridas pelo município de Linhares-ES que, por sua vez, também mantém a instituição de Ensino Superior que abriga o projeto, a FACELI, sendo esta uma das poucas faculdades públicas municipais do país.

Devido a não obrigatoriedade de municípios em gerir instituições de Ensino Superior públicas, estando a modalidade mais restrita a estados e ao governo federal, a FACELI enfrenta resistência em alguns níveis no município, seja por forças políticas que se voltam contra sua existência, seja por alguns entes internos, como outras instituições particulares superiores de ensino.

A FACELI, uma autarquia pública municipal, criada em 1994, localizada no maior município do Espírito Santo, é a única Faculdade de Ensino Superior pública da região, e sua permanência no município, como indicam pesquisas, gera resultados satisfatórios para a população e de localidades vizinhas. Sem elencar todos os pontos positivos da instituição para a comunidade, uma vez que ela oferece três formações distintas, concentrar-nos-emos somente na importância da instituição para a Educação Básica da cidade de Linhares.

Linhares possui uma vasta rede pública municipal que oferta a Educação Infantil e o Ensino Fundamental. Grande parte dos professores da rede foram formados no Curso de Pedagogia dessa Instituição Pública de Ensino Superior, sendo hoje a instituição que mais habilita professores para a Educação Infantil e os primeiros anos do Ensino Fundamental na cidade.

A formação desses profissionais, dentro do próprio contexto cultural da região, já é imensamente importante como investimento do município, mas, mais do que isso, a FACELI desenvolve inúmeros projetos em parceria com as escolas de Educação Básica e Ensino Infantil. No seio da instituição ainda se fazem presentes projetos de 
pesquisas na área educacional, bem como projetos de estágios remunerados ou não, cujos entes participantes são os alunos ali matriculados.

Professores da instituição responsáveis pelas ementas de Práticas de Ensino e Literatura Infantil e Juvenil também buscaram contribuir para a formação de professores e para a relação entre Ensino Superior e comunidade. Daí surgiu a ideia do projeto Conto de Fadas na Educação Infantil. Uma das justificativas para o desenvolvimento do projeto ocorreu pelo fato de alunos da instituição observarem, na prática de estágio, que a leitura é trabalhada em sala, quase sempre, tão somente, como um processo de decodificação de significantes por meio de textos compartimentados. A leitura literária, cotidianamente, acabava sendo relegada, na visão dos alunos.

Segundo pesquisas na área de formação leitora, ao não se utilizarem da literatura ou ao fazê-lo de forma precária, os docentes não propiciam aos estudantes a criação do hábito de ler. A leitura acaba por tornar-se, assim, cansativa e sem significado para a maioria dos estudantes, é o que afirma Kleiman: "A leitura é vista pelo corpo discente como algo massacrante, imposta pelos mestres" (KLEIMAN, 2008, p. 27). Isso ocorre devido a sua aplicação ter sido feita de modo incorreto desde as séries iniciais, privilegiando-se a forma e não o significado dos textos. Na sala de aula, os textos são fragmentos descontextualizados, como afirma Soares (2003, p. 54), "geralmente frutos de recortes de textos originais para se adequarem ao livro didático" (SOARES, 2003, p. 54).

Quando questionados acerca do valor da formação leitora, muitos docentes, no entanto, afirmam que os alunos que não possuem a habilidade da leitura, consequentemente, apresentam dificuldades em todas as disciplinas, pois o discente precisa ler para que assim consigam compreender. No entanto, os mestres, mesmo diante de tal constatação, não inserem a literatura em suas aulas, seja por acomodação, falta de material e/ou espaço para tal ou ainda por faltar-lhes também o hábito de ler, fruto, muitas vezes, de uma formação precária. Tudo isso corrobora para o fracasso no que concerne à formação de leitores na Educação Básica, fato que ocorre também na cidade de Linhares.

A partir de tais constatações, buscou-se realizar um projeto, em espaço escolar, 
a fim de ajudar docentes, em atividade, a inserir a literatura infantil de modo prazeroso na rotina de estudantes da Educação Infantil a partir de jogos, teatros e brincadeiras. Como o trabalho também busca imergir graduandos do curso de Pedagogia nesses meios, assim, procura-se instituir na graduação a experiência da prática com a leitura e a formação leitora.

\section{A literatura e a formação do jovem leitor no espaço escolar}

A formação de leitores, na Educação Básica, pode ser apontada como um dos grandes fracassos na educação pública e, consequentemente, um empecilho para a aprendizagem de qualidade. Silva (2009) aponta fatores ligados ao processo pedagógico como razões para o fracasso da formação leitora no Brasil. Um dos motivos para tal desinteresse, apontado pelo autor, pode estar na escolha realizada pelo professor que, muitas vezes, não garante aos alunos opções de leitura que estejam de acordo com o grau cognitivo ou campo de interesse dos educandos.

Formar jovens leitores é um desafio educacional. Cabe ao professor, nesse processo, ser um mediador de saberes e não somente o construtor daquilo que Silva (2009, p. 28) caracteriza como "uma prática homogênea de formação leitora, utilizando o texto para fim tão somente pedagógico”. Geraldi afirma:

Não pode o professor usar a leitura para outros fins, como pretexto para desenvolver outra atividade: dramatizar uma narrativa, ilustrar uma estória, por exemplo. O tipo de leitura em que o intuito de ler por ler se faz gratuitamente, quebra tal paradigma tão alicerçado por professores no ensino fundamental (GERALDI, 1986, p. 26-27).

A fim de romper as barreiras existentes na formação do hábito da leitura, com os alunos do Ensino Fundamental, os docentes e suas práticas pedagógicas terão de estimulá-los de modo diferenciado. Todo apanhado teórico acerca do assunto aborda que a formação leitora que se almeja nas instituições de ensino deveria favorecer o 
aprendizado de forma agradável e estimulante, levando o educando a assimilar e desenvolver uma percepção crítica do contexto em torno.

De acordo com a Base Nacional Comum Curricular - BNCC (2017), cabe à escola promover a leitura de textos literários em sala. O professor de Educação Básica tem como uma de suas funções, segundo esse documento, a incumbência de ter finalidades e objetivos claros ao pesquisar e apresentar propostas de leitura aos seus alunos, para que assim faça uma escolha de leituras mais consciente. Segundo Silva, “o papel da escola é o de formar leitores críticos e autônomos capazes de desenvolver uma leitura crítica de mundo. Contudo, esta noção parece perder-se diante de outras concepções que ainda orientam as práticas escolares” (SILVA, 2009, p.85). O autor relata, também, que pesquisas empíricas atestam a ausência da prática da leitura literária no contexto escolar, e alerta sobre a importância de sua inserção nesse espaço, pois o papel da escola é, antes de tudo, formar leitores capazes de opinar criticamente.

Os espaços escolares nem sempre fornecem acervos para a prática de leitura e, sabe-se, os livros adequados e o espaço fazem parte do processo de formação do gosto pela leitura. Diante disso, Campello afirma que "formar leitores é algo que requer, portanto, condições favoráveis para a prática de leitura, dentre elas destaca-se a necessidade de um acervo considerável nas, geralmente, sucateadas bibliotecas escolares” (CAMPELLO, 2000, p. 40).

Ainda segundo Campello, "a experiência que cada professor tem com uma biblioteca é muito variada. Poucos conhecem uma boa biblioteca, que reúne livros e outros materiais de qualidade" (CAMPELLO, 2000, p.78). Na maioria das escolas, a biblioteca é conhecida como um estoque de livros e de informações e, na maioria das situações, o uso dela não é adequadamente mediado e as atividades realizadas pelos estudantes não são compartilhadas com os mediadores. Silva (2009) alerta para outro problema no que concerne ao trabalho com literatura em sala, a formação docente:

É necessário repensar a formação inicial e continuada dos professores, de modo que o processo de formação docente seja construído e reconstruído em favor de uma nova postura pedagógica, que inclua, com consistência, a leitura do texto literário nas diversas modalidades do ensino [...] (SILVA, 2009, p. 51). 
É importante, também, que os docentes proporcionem aos estudantes um espaço de liberdade em sala de aula, possibilitando a interação com a leitura de forma significativa, como afirma Campello:

Quando o aluno percebe que existe um ambiente de liberdade e respeito naquele local de trabalho na sala de aula que ele pode perceber o texto literário como um produto cultural com o qual interage de forma significativa. A formação de um ambiente de trabalho que possibilite a intervenção dos alunos na aula e no próprio texto literário é responsabilidade do professor [...] (CAMPELLO, 2000 p.19).

Segundo estudos apontados, constatamos a importância da literatura ser inserida como prática constante nos espaços escolares, mas, também, percebe-se a dificuldade para que isso ocorra, uma vez que a falta de acervos, a formação precária de professores e o mau uso do ambiente em sala influenciam constantemente para que a literatura venha sendo motivada de forma errônea, sem que os alunos consigam perceber o texto literário como algo significativo (SILVA, 2009).

\section{O gênero Conto de Fadas no contexto da infância e da educação básica}

O conceito de criança construiu-se ao longo dos tempos. Ariès (1975) destaca que, no passado, a vida era homogênea e não havia distinção entre as fases da infância e a vida adulta. Segundo Ariès , “a arte medieval desconhecia a infância ou não tentava representá-la. É difícil crer que essa ausência se devesse à incompetência ou a falta de habilidade. É mais provável que não houvesse lugar para a infância nesse mundo” (ARIÈS, 1975, p. 50).

A partir dos sete anos, no período medieval, as crianças começavam trabalhar nos comércios e nas colheitas. $\mathrm{Na}$ época não existia uma literatura voltada à infância. A educação ocorria pela aprendizagem de "técnicas", a formação era prática, aprendia-se imitando o adulto. A partir do Renascimento Italiano, no século XV, inicia-se uma mudança nesse quadro, Passeti assim descreve a criança no período: 
[...] a criança passa a ser vista um ser inacabado, vista como um corpo que precisa de outros corpos para sobreviver, desde a satisfação de suas necessidades mais elementares, como alimentar-se. Os primeiros anos de vida são para ela, o tempo das aprendizagens do meio que a cerca. Brinca com outras crianças da sua mesma idade e até maiores do que ela; arrisca-se em busca de saberes que lhe poderão ser úteis para viver em comunidade (PASSETI, 2003 p. 1-2).

Com o avanço da burguesia, no século XVIII, fortalece-se o patriarcado, a família organiza-se em núcleos e o adulto começa a dar outro status à criança. Diversos autores começam a estudar o universo da infância e percebe-se, ainda nessa época, a partir desses estudos, que a criança possui conflitos, medos, dúvidas e contradições, não por desconhecer a realidade, mas por trazer em si a imagem projetada do adulto.

A imagem da criança é, assim, o reflexo do que o adulto e a sociedade pensam de si mesmos. Mas este reflexo não é ilusão; tende, ao contrário, a tornar-se realidade. Com efeito, a representação da criança assim elaborada, transforma-se, pouco a pouco, em realidade da criança. Esta dirige certas exigências ao adulto e à sociedade, em função de suas necessidades essenciais (ZILBERMAN, 2005, p. 18).

Nesse período, surgem as primeiras instituições formais de ensino para crianças e, a partir de então, agora em abordagem mais institucional, passou-se a ter ainda um novo olhar voltado às crianças, sendo considerados também seus níveis de aprendizagem e socialização, que atendessem à maturação cognitiva dos infantes.

A história da literatura infantil e juvenil atrela-se à história da concepção de infância. Os primeiros livros escritos para crianças foram produzidos somente no final do século XVII e durante o século XVIII, antes disso não se escrevia para elas, uma vez que não existia infância. Crianças e adultos compartilhavam dos mesmos eventos sociais entre a vida e a rotina.

A literatura infantil, no que se refere à produção escrita, surgiu no século XVIII, impulsionada pelos estudos folclóricos, impulsionada pelo nacionalismo, mas também a fim de atender a esse novo público que se formava. Seguindo o espírito conservador bur- 
guês e com a função de educar moralmente as crianças, os primeiros livros infantis tinham uma estrutura maniqueísta, a fim de demarcar claramente o bem a ser aprendido e o mal a ser desprezado (ARIÈS, 1975). Os gêneros infantis ainda se incluem nessa tradição.

No começo, a literatura infantil alimenta-se de obras destinadas a outros fins, aos leitores adultos, cujas histórias contadas eram da mesma forma narradas às crianças, essas narrativas são adaptadas ao universo infantil. Com a mudança de valores, a partir do século XVIII, geraram-se as adaptações aos ouvintes dos contos populares, convertendo-os em livros para crianças, os populares Contos de Fadas.

A importância desse gênero para a formação da criança já parece ter sido comprovada por inúmeros estudos. Bettelheim, um dos principais estudiosos do tema, acredita que, "através dos contos de fadas a criança alicerça seu sofrimento com conhecimentos, pois quanto mais alternativas ficcionais forem oferecidas para as crianças, mais elas conseguem elaborar e organizar seus dramas" (BETTELHEIM, 2007, P. 78), sendo o gênero, uma forma de enriquecimento interior do sujeito no início de sua formação.

Nos contos de fadas, apesar de adaptados ao espirito maniqueísta burguês, sobressai-se a natureza popular desse tipo de produção, e todo seu fôlego cultural. Desse modo, essas histórias cumprem um papel mais que somente educativo, uma vez que se alcança, por meio de seu enredo, uma visão de mundo mais alargada, permitindo ao leitor inúmeras interpretações, indagações e análises sobre diversas perspectivas. Bettelheim afirma:

Os contos de fadas, à diferença de qualquer outra forma de literatura, dirigem a criança para a descoberta de sua identidade e comunicação, e também sugerem as experiências que são necessárias para desenvolver ainda mais o caráter. Os contos de fadas declaram que uma vida compensadora e boa está ao alcance da pessoa apesar da adversidade - mas somente se ela não se intimidar com as lutas do destino, sem as quais não se adquire verdadeira identidade. Estas estórias prometem à criança que, se ela ousar se engajar nesta busca atemorizante, os poderes benevolentes virão em sua ajuda, e ela o conseguirá. (BETTELHEIM, 2007, p. 32)

As bibliotecas presentes nas escolas possuem o intuito de estimular as crianças a ler, mas poucas delas possuem um acervo com bons livros. É preciso ter em mente 
que este público, ao ler um livro, não o faz superficialmente e apenas de forma maniqueísta; a criança procura um significado em cada palavra e se lança sem medo na jornada de desvelar os segredos dos símbolos que compõem a narrativa.

\section{A abordagem da literatura infantil em espaço escolar}

De acordo com Cosson (2012), na escola, a leitura literária tem a função de ajudar a "ler melhor", não apenas porque possibilita a criação do hábito da leitura ou porque seja prazerosa, mas sim, e, sobretudo, porque nos fornece, como nenhum outro tipo de leitura faz, os instrumentos necessários para conhecer e articular com proficiência o mundo feito linguagem.

Um meio de levar a literatura aos espaços escolares se dá por meio de projetos de leitura. No entanto, a leitura é, muitas vezes, tratada de modo mecanizada pelos professores, com o intuito de cumprir um currículo, sem a preocupação de ser peça fundamental para a construção leitora do aluno, em sua leitura de mundo e até mesmo na formação crítica e pessoal:

Outra concepção de leitura, observada com maior frequência, denota uma decodificação de signos linguísticos, por meio do aprendizado estabelecido a partir do condicionamento estímulo respostas. Tal conceito, de perspectiva behavorista-skinneriana, ignora a profundidade da experiência do contato do indivíduo com os elementos da comunicação humana (SILVA, 2009, p. 67).

Inúmeras vezes percebe-se que o projeto de leitura, quando desenvolvido em ambiente escolar, é tratado como uma disciplina, com horário e data reservados, como se a leitura possuísse um tempo determinado para ocorrer.

Nota-se que ocorre a falta de estrutura e planejamento para a formação leitora. A abordagem da literatura nos projetos de leitura em sala de aula mostra-se superficial, tanto no tempo, no planejamento e na infraestrutura escolar.

Cosson afirma que é fundamental que seja colocado como foco das práticas 
literárias na escola a leitura efetiva dos textos, e não as informações das disciplinas que ajudam a construir essas leituras. Essa leitura não pode ser realizada simplesmente pelo prazer absoluto de ler. "[...] Por fim, devemos compreender que o letramento literário é uma prática social e, como tal, responsabilidade da escola" (COSSON, 2012, p. 23). Por isso, os projetos de leitura deveriam ser mais estruturados e atrativos.

A experiência literária não só nos permite saber da vida por meio da experiência do outro, como também vivenciar essa experiência. Ou seja, a ficção feita palavra na narrativa e a palavra feita matéria na poesia são processos formativos tanto da linguagem quanto do leitor e do escritor. (COSSON, 2012, p. 17)

A leitura literária deve ser incentivada. O aluno, segundo Silva (2000), precisa ter a liberdade de ler o que gosta e com o que se identifica, a escola precisa tratá-lo como um sujeito de educação, uma vez que ele constrói seu conhecimento. Os planejamentos e as metodologias a serem utilizadas para a formação leitora desses alunos deveriam ir ao encontro dos interesses e dificuldades desses alunos.

\section{Projeto de extensão: \\ Contos de Fadas na Educação Infantil}

O projeto - Contos de Fadas na Educação Infantil - ocorre desde o primeiro semestre de 2018. Ele foi idealizado pela professora adjunta de Literatura Infantojuvenil da Faculdade de Ensino Superior de Linhares em parceria com a professora da disciplina de Atividades Práticas. Essa instituição localiza-se no município de Linhares - ES. $\mathrm{Na}$ atualidade, abriga três cursos: Administração, Direito e Pedagogia, este último, no caso, desenvolve o projeto em questão.

O projeto de extensão - Contos de Fadas na Educação Infantil - leva, desde 2018, os saberes desenvolvidos na instituição pelos alunos de Pedagogia a escolas públicas do município de Linhares e de cidades em torno. A cada semestre, 40 alunos do curso de Pedagogia participam de um curso teórico acerca do gênero Contos de 
Fadas. Na formação em questão, estuda-se desde a história desse gênero, seus principais autores, técnicas de contação de histórias e a produção de material pedagógico.

Após a escolha das escolas de Educação Infantil, sempre mapeando instituições que ainda não foram atendidas pelo projeto, os alunos da instituição são recebidos pelas equipes dessas escolas e o trabalho é desenvolvido.

O projeto visa a atingir estudantes iniciantes de Pedagogia e tem sido o primeiro contato de alguns desses alunos com a prática pedagógica, muitos deles relatam, inclusive, que se havia dúvidas na escolha da graduação, elas acabaram sendo esclarecidas ao fazerem parte do projeto em questão.

Ao longo dos quatro semestres em que o projeto tem sido desenvolvido, 20 (vinte) escolas foram atendidas, sendo 03 fora do município e 17 do município de Linhares. Até o presente momento todas as escolas atendidas foram públicas e mantidas pelo município. $\mathrm{Na}$ avaliação do projeto, que se faz rotineiramente nas escolas visitadas pelos estudantes, a atuação dos acadêmicos foi vista como positiva em todas elas, sem que nenhuma crítica sequer fosse registrada. Todas as escolas também demonstraram anseio de receber o projeto novamente.

Os registros do projeto de extensão, em execução, sejam por meio de fotos, vídeos, relatos e materiais diversos, têm sido arquivados pelas professoras responsáveis. Já há um farto conjunto de registros e de ideias que brotaram da mente dos 160 participantes diretos desse trabalho. Abaixo, seguem alguns relatos a fim de comprovar não só a existência do projeto, mas, sobretudo, a criatividade e a disposição dos envolvidos na disseminação do gênero Contos de Fadas em turmas de Educação Infantil. Consideramos, pois, uma experiência que o leve a questionar e tecer novas concepções acerca da leitura. Assim, esse trabalho visa apresentar a importância dos livros e dos contos na iniciação da criança no mundo da leitura.

Descrevemos alguns relatos de professoras da Educação Infantil quanto à importância do projeto Contos de Fadas na Educação Infantil, reafirmando a ressignificação do enlace entre Escola de Ensino Superior e Educação Básica.

Os contos de fadas são de suma importância no mundo das crianças. E a presença dos teatros com a participação dos estudantes do Cur- 
so de Pedagogia tem trazido mais prazer a minha prática docente (Professora 1, 2019).

É muito interessante para as crianças a participação de outras pessoas da comunidade na contribuição do nosso trabalho na formação de leitores (Professora 2, 2018).

A interação dos estudantes do Curso de Pedagogia com as crianças propiciou um momento prazeroso. Foi além da leitura, da apresentação. Propiciou significação, sentidos para a formação dessas crianças (Professora 3, 2019).

Foi muito importante o momento de reflexões proporcionadas às crianças. As intencionalidades de contribuir com a formação leitora e ao mesmo tempo propiciar interações e situações de significavas de dialogo e aprendizagens (Professora 4, 2018).

$\mathrm{O}$ interessante é que a presença de vocês com a encenação teatral as crianças se sentiram participantes da história, adquiriram tranquilidade e conseguiram compreender sentimentos e fantasias (Professora 5, 2019).

A escola está de portas abertas para a literatura infantil e os contos de fadas. Vocês têm nos ajudado em nosso projeto de leitura e contribuído com o desenvolvimento do trabalho (Diretora, 2018).

Podemos constatar, a partir dos relatos acima, que a leitura literária e, especialmente, os Contos de Fadas são de extrema importância para as crianças e torna-se praticamente um ato fundamental nos currículos escolares. Notamos, também, que a parceria entre Escola de Ensino Superior e Escola Básica tem fundamental importância, uma vez que esse projeto de extensão tem por finalidade, também, possibilitar a inserção de acadêmicos no cotidiano da educação básica. Durante o projeto, o acadêmico vivencia o cotidiano de uma escola de educação básica, buscando conhecer, interagir, promover um maior intercâmbio com as escolas, crianças e professores e discutir em sala de aula subsídios teórico-metodológicos que possam contribuir para a melhoria da formação inicial.

Teoria e prática, articuladas entre si, sustentam os alicerces da formação docente inicial e continuada. Desse modo, aproximar os acadêmicos do cotidiano in loco dá sentido ao estudo da teoria. Compreender a relação teoria-prática constitui um eixo de valorização do curso como momento de práxis, que contribui para a formação e o desenvolvimento do futuro professor em busca de sua formação docente. 
Gatti e Barreto (2009), em estudos recentes sobre os impasses e desafios postos aos professores do Brasil, ressaltaram a dificuldade para formar bons quadros para a docência. Entre os problemas identificados, apontam a debilidade da formação profissional ministrada por muitas instituições de ensino, atuando de maneira desarticulada à prática, faltando entrosamento entre teoria e prática. A situação é agravada pela forte tradição disciplinar brasileira, que se opõe às tentativas de se alcançar uma ação escolar interdisciplinar.

De acordo com Lüdke e Cruz (2005, p. 85), os cursos de formação de professores no Brasil têm sofrido as consequências de um defeito congênito de sua constituição: a separação entre teoria e prática no esforço de formação, colocando, geralmente em posição precedente, a teoria e sempre depois a atividade prática, por meio de estágios de duração insuficiente e, sobretudo, de concepção precária.

Não é possível nos determos mais sobre esse ponto que exige, porém, atenção cuidadosa da construção do saber docente, hoje tão discutida por autores que se preocupam exatamente com a dissociação entre teoria e prática. Os currículos dos cursos de formação docente vêm ganhando ressignificação, incorporando preocupações da natureza pedagógica vinculados à prática.

Num esforço de resgatar a importância devida à dimensão da prática, este projeto de extensão ganhou força nos cotidianos de escolas de Educação Infantil, propiciando para crianças a literatura infantil na formação de leitores e contribuindo com a integração teoria e prática nos cursos de formação docente.

No que diz respeito aos saberes e práticas dos acadêmicos participantes do projeto, eles nos presentearam com falas de grande expressividade, justamente por reforçar que a experiência privilegia momentos de aprendizagens significativas em sua formação docente.

Abordamos alguns registros da experiência de acadêmicos do Curso de Pedagogia envolvidos nesse projeto:

Foi muito interessante despertar as crianças para o fantástico mundo do conto de fadas (Estudante 1, 2018).

A experiência na prática a partir do conto de fada trouxe para minha 
formação algo inusitado e para as crianças o prazer da leitura e pensamentos significativos (Estudante 6, 2019).

Foi o meu primeiro momento do curso vivenciado com crianças que me permitiu descobrir no rosto das crianças o prazer de ensinar e compartilhar momentos prazerosos de aprendizagens a partir dos contos de fadas (Estudante 2, 2019).

Que prazeroso conhecer, de fato, a realidade da sala de aula (Estudante 3, 2018).

O contato direto com as crianças me proporcionou o desejo de ser professora e constatei como o Conto de Fada encenado e trabalhado com as crianças tem sido gratificante para a formação leitora e humana das crianças (estudante 4, 2018).

Foi maravilhoso conviver com as crianças no cotidiano da escola de Educação Infantil e proporcioná-las momentos de prazer a partir de experiências práticas (Estudante 9, 2019).

Considerando os relatos descritos, é possível afirmar a relevância da relação entre teoria e prática na formação inicial docente e a importância atribuída durante o processo formativo dos acadêmicos. No contexto da práxis, situamos a formação inicial docente, partindo do pressuposto de que o ensino e a aprendizagem se tornam significativos quando construídos no coletivo. É por meio da experiência na prática que o professor em formação dá sentido a sua profissão. É nesse sentido que o estágio supervisionado como atividade teórico-prática torna-se relevante na vida do futuro professor.

As figuras 1 e 2 mostram os acadêmicos do Curso de Graduação em Pedagogia da Faculdade de Ensino Superior de Linhares e as crianças da Educação Infantil numa representação teatral do conto sobre "Branca de Neve e os Sete Anões" dos Irmãos Grimm e o conto o "Patinho Feio". 


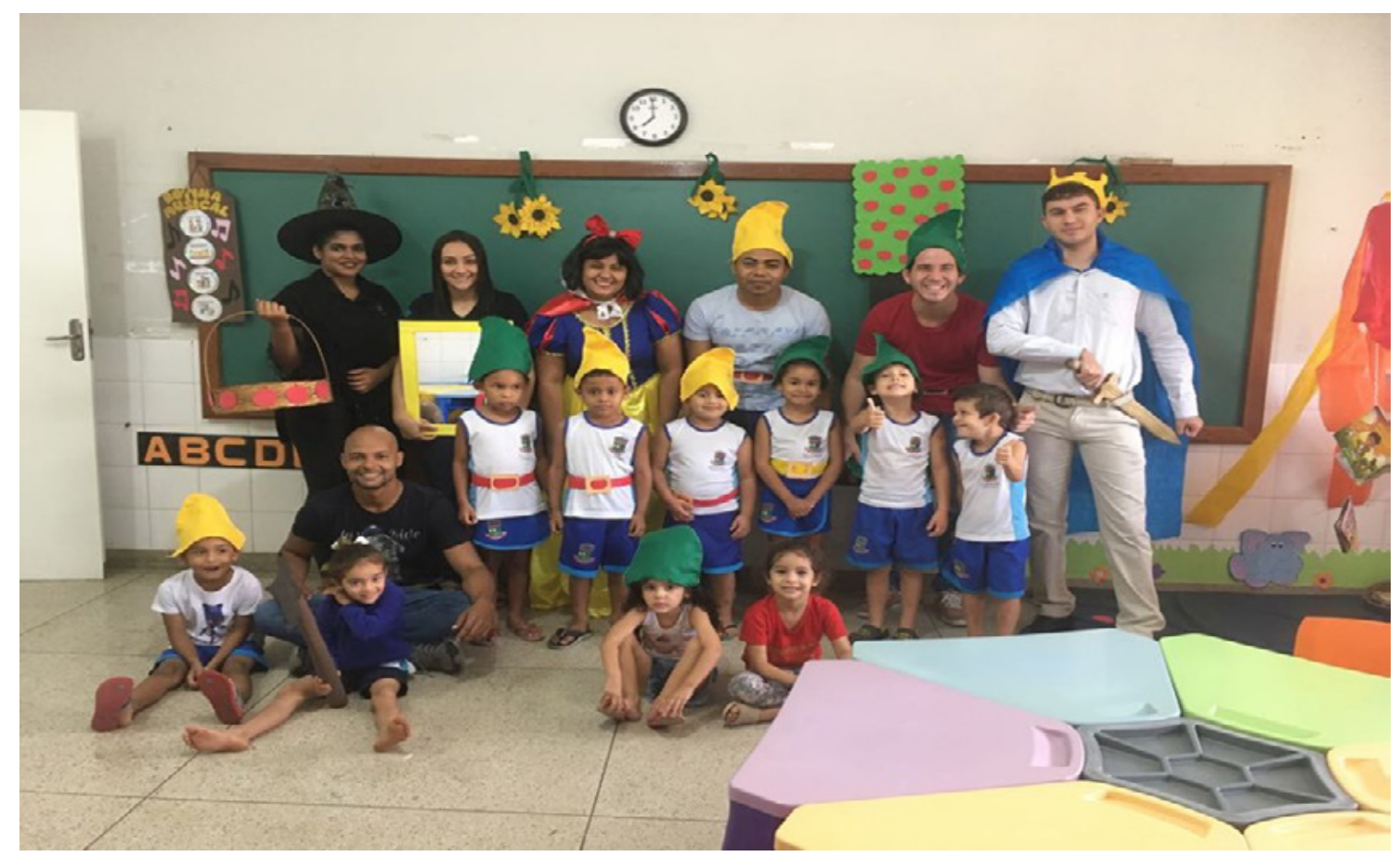

Figura 1: Acadêmicos e crianças da Educação Infantil

Fonte: Arquivo das autoras (2019).

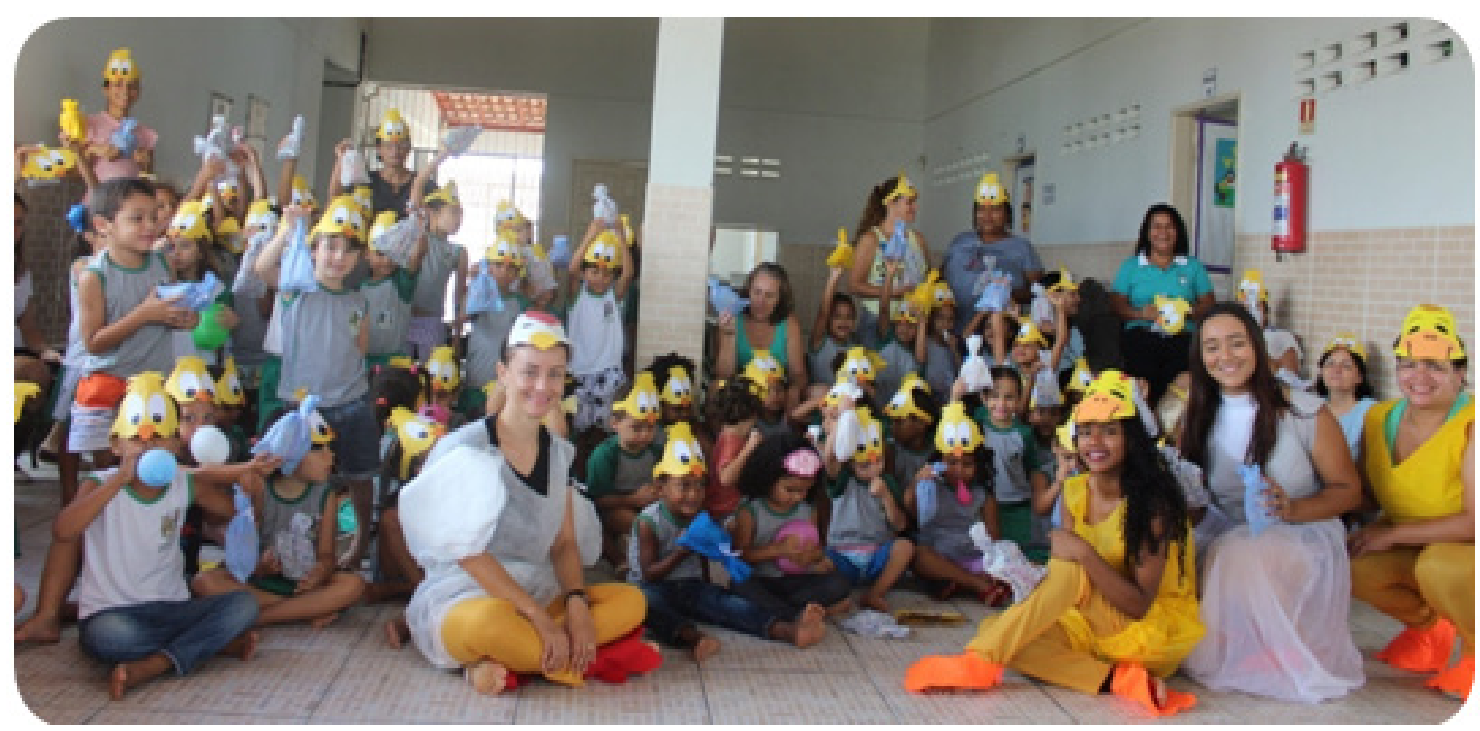

Figura 2: Acadêmicos e crianças da Educação Infantil

Fonte: Arquivo das autoras (2019).

De acordo com Freire (1989), a leitura deve promover no leitor um avanço acerca da inteligência do mundo, uma tomada de consciência da posição do indivíduo 
dentro da sociedade, para entender as relações políticas e seu papel nessas relações. Nesse sentido, a prática da leitura literária infantil é essencial em espaços escolares e, especialmente, vida cotidiana dos nossos estudantes. A literatura desde a infância é algo que potencializa as habilidades da vida adulta em sociedade, configurando-se em um viés com múltiplas possibilidades na prática pedagógica.

\section{Considerações finais}

No decorrer do projeto de extensão Contos de Fadas na Educação Infantil (ainda em andamento), tem sido possível refletir sobre a importância da literatura infantil para a imaginação do educando, sendo ela necessária para a construção do cognitivo e da autonomia do aluno. Diante disso, busca-se, pelo projeto, compreender um pouco mais sobre o que é a literatura, suas particularidades mais relevantes, correlacionando com suas práxis dentro da sala de aula.

Sendo assim, conclui-se que o trabalho com o gênero Contos de Fada é de extrema relevância para que os alunos construam sua autonomia e tornem-se críticos, capazes de opinar acerca dos contextos em torno, tendo também papel primordial para o procedimento de aprendizagem do indivíduo, propiciando-lhe a chance de ampliar, modificar e engrandecer sua experiência de vida.

Além do mais, a literatura se faz importante para a linguagem do aluno, e é de grande importância que os educadores planejem momentos de comunicação: conversas, debates orais e a forma mais interessante para que isso aconteça é a leitura de livros literários.

Ao examinar a literatura infantil nos anos iniciais, verificou-se que ela é um instrumento marcante para o educador utilizar meios pedagógicos para estimular a leitura nos alunos. Portanto, observa-se que as teorias pesquisadas se correlacionam com a prática, pois, ela realmente traz resultados na aprendizagem assim como dizem os autores estudados.

Por meio da observação, foi possível verificar como os docentes trabalham a 
literatura em sala, e como essa prática influencia na vida dos alunos. Além disso, por ser uma pesquisa de campo, vale ressaltar que tivemos a oportunidade de presenciar questionamentos a respeito da entrevista realizada com os professores, e recebemos como resultado que os alunos gostam de ler livros.

De acordo com a coleta de dados, a literatura infantil e juvenil desperta um olhar diferenciado pela leitura, de forma que leva as crianças a criarem um hábito em suas rotinas diárias, e que desperta a curiosidade dos alunos para estudar mais sobre os acervos literários, tornando-os pesquisadores de novos conhecimentos, conduzindo-os para uma forma significativa de ensinar e aprender.

Com este projeto, pretendemos provocar nos envolvidos o despertar da leitura de livros literários para o público de séries iniciais, trazendo, assim, a importância da leitura em si, como ela deve ser ressaltada em sala de aula e o que ela provoca nos estudantes quando ocorre esse contato. 


\section{Referências}

Ariès, Philippe. História Social da Criança e da Família. 2 Edição. Rio de Janeiro: Guanabara, 1975.

FREIRE, Paulo. A importância do ato de ler: em três artigos que se completam. São Paulo. Editora Cortez, 1989.

GATTI, Bernardete Angelina; BARRETTO, Elba Siqueira de Sá. Professores do Brasil: impasses e desafios. Brasília: UNESCO, 2009.

BETTELHEIM, B. A Psicanálise dos Contos de Fadas. Rio de Janeiro: Paz e Terra, 2007.

CAMPELLO, S. B. et al. A coleção da biblioteca escolar na perspectiva dos Parâmetros Curriculares Nacionais. Informação \& Informação, Londrina, v.6, n.2, p.71-88, 2001.

COSSON, Rildo. Letramento Literário: teoria e prática. 2. Ed. São Paulo: Editora Contexto, 2012.

GERALDI, João Wanderley. O texto na sala de aula. Cascavel: ASSOESTE, 1984.

LÜDKE, Menga; CRUZ Giseli Barreto e. Aproximando universidade e escola de educação básica pela pesquisa. Cadernos de Pesquisa, v. 35, n. 125, maio/ago. 2005.

PASSETTI, E. Anarquismos e sociedade de controle. São Paulo: Cortez, 2003.

SILVA, Vera Maria Tietzmann. Literatura infantil brasileira: um guia para professores $e$ promotores de leitura. 2. Ed. Goiânia, GO.: Cânone Editorial, 2009. 
ZILBERMAN, Regina. Como e por que ler a literatura infantil brasileira. Rio de Janeiro, R.S.: Objetiva, 2005. 